\title{
Clinical significance of tumor-infiltrating lymphocytes in breast cancer
}

\author{
Sasha E. Stanton * (D) and Mary L. Disis
}

\begin{abstract}
Tumor infiltrating lymphocytes (TIL) play an essential role in mediating response to chemotherapy and improving clinical outcomes in all subtypes of breast cancer. Triple negative breast cancers (TN) are most likely to have tumors with $>50 \%$ lymphocytic infiltrate, termed lymphocyte predominant breast cancer, and derive the greatest survival benefit from each $10 \%$ increase in TIL. The majority of HER2 ${ }^{+}$breast cancers have similar level of immune infiltrate as TN breast cancer yet the presence of TILs has not shown the same survival benefit. For HER2 ${ }^{+}$breast cancers,

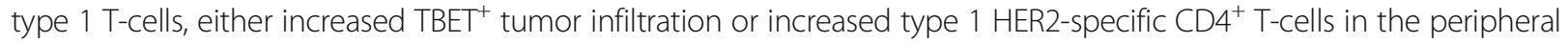
blood, are associated with better outcomes. Hormone receptor positive HER2 negative tumors tend to have the least immune infiltrate yet are the only breast cancer subtype to show worse prognosis with increased FOXP3 regulatory T-cell infiltrate. Notably, all breast cancer subtypes have tumors with low, intermediate, or high TIL infiltrate. Tumors with high TILs may also have increased PD-L1 expression which might be the reason that TN breast cancer seems to demonstrate the most robust clinical response to immune checkpoint inhibitor therapy but further investigation is needed. Tumors with intermediate or low levels of pre-treatment immune infiltrate, on the other hand, may benefit from an intervention that may increase TIL, particularly type $1 \mathrm{~T}$-cells. Examples of these interventions include specific types of cytotoxic chemotherapy, radiation, or vaccine therapy. Therefore, the systematic evaluation of TIL and specific populations of TIL may be able to both guide prognosis and the appropriate sequencing of therapies in breast cancer.
\end{abstract}

Keywords: Breast cancer, Tumor infiltrating lymphocytes, CD8 T-cell, FOXP3

\section{Background}

Infiltration of immune cells, particularly infiltration of anti-tumor type 1 lymphocytes, has predicted improved prognosis in many different tumor types including colon, ovarian, lung and breast cancer [1-4]. Historically breast cancer was not thought to be immunologically active, particularly when compared to tumors such as melanoma. However recent evidence has emerged that tumor infiltrating lymphocytes (TILs) present in breast cancer prior to treatment can predict response to therapy and improved prognosis $[4,5]$.

Not only does the amount of lymphocytic infiltration but also the phenotype of that infiltrate determine clinical outcome. Type 1 T-cells are associated with favorable prognosis. $\mathrm{CD} 4^{+}$T-helper 1 (Th1) cells facilitate

\footnotetext{
* Correspondence: sestant2@uw.edu

Tumor Vaccine Group, Center for Translational Medicine in Women's Health, University of Washington, 850 Republican Street, 2nd Floor, Box 358050, Seattle, WA 98195-8050, USA
}

antigen presentation through cytokine secretion and activation of antigen presenting cells. $\mathrm{CD} 8^{+}$cytotoxic T-cells (CTL) are essential for tumor destruction [6]. On the other hand, type $2 \mathrm{CD} 4^{+} \mathrm{T}$-helper cells (Th2), including Forkhead box P3 (FOXP3) $\mathrm{CD}_{4}^{+}$regulatory T-cells, inhibit CTL function, support proliferation of B-lymphocytes, and may promote an anti-inflammatory immune response that could enhance tumor growth [7].

\section{Lymphocyte levels in breast cancer and prognosis}

The adaptive immune response to breast cancer can be seen in infiltrating breast lesions as early as benign breast atypia and increases in density as invasive malignancy develops. In one retrospective study of 53 mastectomy samples, increased B-cell and T-cell immune infiltrate was identified in benign ductal hyperplasia, increased in ductal carcinoma in situ (DCIS), and was found in the greatest magnitude in invasive breast cancer [8]. In a study of 27 DCIS patients, all tumors demonstrated some level of TIL and $78 \%$ of DCIS had $>5 \%$ infiltrate.

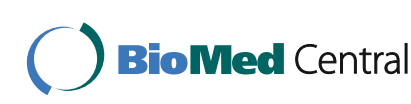

(C) 2016 The Author(s). Open Access This article is distributed under the terms of the Creative Commons Attribution 4.0 International License (http://creativecommons.org/licenses/by/4.0/), which permits unrestricted use, distribution, and reproduction in any medium, provided you give appropriate credit to the original author(s) and the source, provide a link to the Creative Commons license, and indicate if changes were made. The Creative Commons Public Domain Dedication waiver (http://creativecommons.org/publicdomain/zero/1.0/) applies to the data made available in this article, unless otherwise stated. 
High lymphocytic infiltrate was associated with young age and triple negative (TN) DCIS, similar to invasive cancer, with all TN DCIS $(p=0.0008)$ having programed deathligand 1 (PD-L1) expression [9]. The phenotype of the $\mathrm{T}$-cell response has also been shown to predict prognosis in DCIS. In a study of 62 DCIS samples, FOXP3 ${ }^{+}$ infiltrate above the mean predicted decreased relapse free survival (RFS) (HR 2.8; $95 \%$ CI 0.99-7.99, $p=0.05$ ) [10]. Conversely, increased expression of a Th1 gene signature predicted improved survival in 31 patients with DCIS [11]. Tumor lymphocytic infiltrate may be able to be developed for use to stratify risk of recurrence and need for aggressive therapies in DCIS, and immune therapies may provide well-tolerated approaches to explore for improved DCIS treatment [12].

In invasive breast cancer, the greatest clinical benefit is seen in tumors with $>50 \%$ lymphocytic infiltrate (lymphocyte predominant breast cancer (LPBC)). In patients with locally advanced breast cancer treated with neoadjuvant chemotherapy, patients with LPBC had a $40 \%$ pathologic complete response (pCR) (OR 1.38, $p=$ $0.01295 \%$ CI 1.08-1.78) as compared to $7 \%$ pCR in patients with tumors that had no lymphocytic infiltrate [4]. Increased $\mathrm{CD}^{+} \mathrm{T}$-cells have also been shown to predict improved clinical outcome, with higher intratumoral $\mathrm{CD}^{+}$T-cell infiltrate associated with improved breast cancer specific survival (HR $0.5595 \%$ CI, 0.39 to $0.78 p=0.001$ ) in one large study of 1334 patients [13]. This has not been replicated in other clinical studies [14-16]. Infiltration of $\mathrm{TBET}^{+}$cells (T-box transcription factor TBX21, a marker of type 1 T-cells) can also predict improved disease free survival (DFS) in all breast cancer subtypes with breast cancer patients with tumors containing $<30 \mathrm{TBET}^{+}$cells having decreased DFS as compared to patients with tumors containing $\geq 30 \mathrm{TBET}^{+}$ cells (RR $5.6295 \%$ CI 1.48-50.19 $p=0.0027 n=617$ ) [17]. On the other hand, the presence of the Th2 marker $\mathrm{FOXP}^{+}$in the tumor has been associated with worse prognosis. In an evaluation of over 200 breast cancers, patients with tumors containing greater than $15 \mathrm{FOXP3}^{+}$cells had decreased RFS $(p=0.04$ HR 1.58, $95 \%$ CI 1.01 to 2.47$)$ and overall survival (OS) $(p=0.07$, HR $1.6295 \%$ CI 0.96 to 2.74) [10]. Even when examining all breast cancer subtypes together, the composition and magnitude of the tumor immune infiltrate affects clinical outcome and demonstrates that breast cancer is an immunogenic tumor. However the impact of TILs on clinical outcome is most evident when the breast cancer subtypes are evaluated separately.

In $\mathrm{HER}_{2}{ }^{+}$and $\mathrm{TN}$ breast cancer, even incremental increases in TILs both in and surrounding the tumor have shown to predict both response to chemotherapy and improved survival in patients [5, 18-20]. Furthermore, LPBC is more common in both TN and HER2 ${ }^{+}$ breast cancers, with a median of $20 \% \mathrm{TN}$ tumors and $16 \% \mathrm{HER}^{+}$tumors having LPBC (Fig. 1a) [21]. One study of $256 \mathrm{TN}$ tumors demonstrated every $10 \%$ increase in TIL correlated with a $17 \%$ decrease in the risk of recurrence $(p=0.023, \mathrm{HR} 0.83 ; 95 \%$ CI $0.71-$ $0.98)$ and a $27 \%$ decreased risk of death $(p=0.035$, HR 0.73; $95 \%$ CI 0.54-0.98) [5]. Similarly, for each $10 \%$ increase in stromal TIL there was $18 \%$ increase in OS (HR $0.8295 \%$ CI 0.69-0.96) in 112 HER2 $^{+}$breast cancer patients [20]. For both $\mathrm{HER}^{+}$and $\mathrm{TN}$ breast cancer, while the best response has been seen in LPBC that have the highest infiltrate, even small increases in TIL lead to incremental increases in improved survival and may suggest that even therapies that modestly increase TIL can benefit clinical outcome in these subtypes.

Both TN and HER2 ${ }^{+}$patients have evidence of $\mathrm{CD}^{+}$ T-cell infiltrate with approximately $60 \%$ of tumors containing $\mathrm{CD}^{+}$T-cells (Fig. 1b) [21]. $\mathrm{CD}^{+}$infiltrate has only been shown to predict a survival benefit in $\mathrm{TN}$ breast cancer; improved breast cancer specific survival was seen with any intratumoral $\mathrm{CD}^{+}$infiltrate $(p=0.001$, HR 0.35 ; $95 \%$ CI 0.23 to $0.54 n=927$ ) (Table 1) [15]. While intratumoral CD ${ }^{+}$T-cells do not predict improved clinical outcome in $\mathrm{HER}^{+}$breast cancer, $\mathrm{TBET}^{+}$tumor infiltrate predicted improved RFS $(p=0.04$ HR 4.76, $95 \%$ CI 1.07 to 20) in 102 HER2 tumors treated with trastuzumab [22]. For HER2 ${ }^{+}$breast cancer, the effect of $\mathrm{CD}^{+}$tumor infiltrate may require hormone positive $\mathrm{HER}^{+}$tumors to be evaluated separately from hormone negative $\mathrm{HER}^{+}$tumors. The only study that stratified $\mathrm{HER}^{+}$tumors by hormone receptor status found that $\mathrm{CD}^{+}$tumor infiltrate was associated with RFS $(p=0.041)$ $(p=0.064$, HR $0.75 \%$ CI $0.51-1.11 n=227)$ in hormone receptor negative HER2 ${ }^{+}$breast cancer but not hormone receptor positive $\mathrm{HER}_{2}{ }^{+}$breast cancer [15]. These data suggest that the immune infiltrate in $\mathrm{HER}^{+}$breast cancer may be more influenced by hormone receptor status rather than HER2 protein overexpression.

As compared to $\mathrm{TN}$ or $\mathrm{HER} 2^{+}$subtypes, hormone receptor positive HER2 negative (HR) tumors both have less TIL and the tumors with LPBC do not show the same improved survival benefit. Only $6 \%$ of HR tumors have LPBC and less than half have $\mathrm{CD}^{+} \mathrm{T}$-cell infiltrate (Fig. 1) [21]. The decreased lymphocytic infiltrate may be due to the expression of the estrogen receptor which has been shown to both promote a Th2 immune environment and decrease MHC class II expression in breast cancer cells [23, 24]. However, HR breast cancer is the only breast cancer subtype where $\mathrm{FOXP3}^{+}$infiltrate predicts a worse survival $[10,21,25]$. In $148 \mathrm{HR}^{+}$ tumors, increased $\mathrm{FOXP}^{+}$infiltrate was associated with a decreased RFS ( $p=0.006$ HR $2.2095 \%$ CI 1.263.85) and OS ( $p=0.006$, HR $2.5795 \%$ CI 1.31-5.60) [10]. Potentially, a therapy that can effectively decrease 


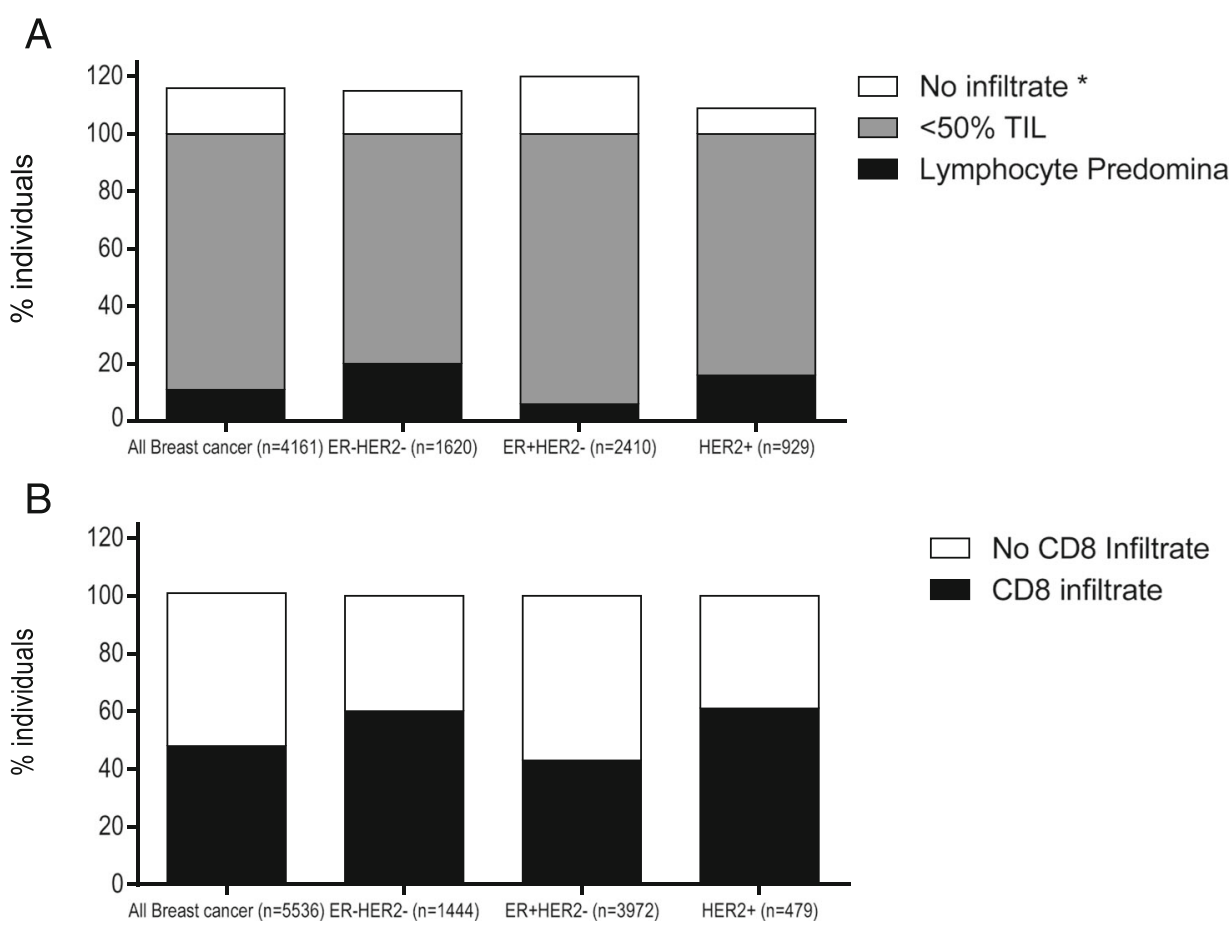

Fig. 1 Most breast cancers have evidence of lymphocytic infiltrates at the time of diagnosis, although the level of infiltrate is modest, and the presence of $\mathrm{CD}^{+}$infiltrate varies between the breast cancer subtypes. The \% individuals ( $x$-axis) are shown for: a no evidence of TIL (white), TIL $<50 \%$ (medium grey), and LBPC (black) data compiled from 6 studies. * Only one to two studies evaluated no infiltrate separately. b Presence of $\mathrm{CD}^{+}$infiltrate (black) or no $\mathrm{CD}^{+}$infiltrate (white), data compiled from 3 studies

$\mathrm{FOXP3}^{+}$infiltrate may increase the magnitude of lymphocytic infiltrate in HR tumors and may improve clinical response in the neoadjuvant setting (Table 2).

\section{Immune checkpoint inhibitor therapy in breast cancer}

PD-L1 expression has been associated with increased TILs and better prognosis in breast cancer. In a study of 45 primary breast cancers, $89 \% \mathrm{PD}-\mathrm{L}^{+}$and $24 \% \mathrm{PD}^{-} \mathrm{L}^{-}$ breast cancers had moderate or diffuse TILs. Furthermore, none of patients that had PD-L1 ${ }^{+}$breast cancer at diagnosis developed distant recurrence whereas $15 \%$ of the patients that had PD-L1 ${ }^{-}$breast cancer at diagnosis did develop distance recurrence [26]. PD-L1 infiltrate has been associated with TN breast cancer and CD8+ T-cell infiltrate (Table 2) [27]. These data suggest that PD-L1 expression is a marker of an immunologically active breast cancer. Although increased TIL has also been associated with increased PD-L1 infiltrate, the association between increased TIL and response to immune checkpoint therapy has not yet been established [28, 29]. Early trials of immune checkpoint inhibitor specific monoclonal antibodies have shown only modest clinical efficacy in breast cancer. None of the breast cancer patients included in the initial pembrolizumab (anti-PD-1) trial showed any response to treatment and the combination of tremelimumab (anti-CTLA4) and exemestane in HR metastatic breast cancer demonstrated development of stable disease as best response in $42 \%$ of patients [30, 31]. Several studies have shown a modest clinical response in $\mathrm{TN}$ breast cancer to pembrolizumab and

Table 1 Effect on outcome of LPBC, CD8+, or FOXP3 tumor infiltrate by subtype

\begin{tabular}{|c|c|c|c|c|c|c|}
\hline \multirow[b]{3}{*}{ Immune infiltrate } & \multicolumn{6}{|c|}{ Breast cancer subtype } \\
\hline & \multicolumn{2}{|l|}{$\overline{T N}$} & \multicolumn{2}{|l|}{$\mathrm{HR}+$} & \multicolumn{2}{|l|}{ HER2+ } \\
\hline & DFS or RFS & OS or DSS & DFS or RFS & OS or DSS & DFS or RFS & OS or DSS \\
\hline LPBC & +++ & +++ & & & ++ & + \\
\hline Elevated CD8+ & + & +++ & & + & $+($ TBET $)$ & \\
\hline Elevated FOXP3 & & & - & - & & \\
\hline
\end{tabular}

Abbreviations: DFS disease free survival, RFS relapse free survival, OS overall survival, DSS disease specific survival, LPBC lymphocyte predominant breast cancer, $T N$ triple negative, $H R$ hormone receptor

+++ Increased (>2 sources); ++ (increased 2 sources) + Increased (one source); - Decreased (one source) 
Table 2 Biomarker staining by $\mathrm{IHC}$ and prognosis in breast cancer subtypes

\begin{tabular}{llll}
\hline Marker & Measurement & Good prognosis & $\begin{array}{l}\text { Breast cancer } \\
\text { subtype }\end{array}$ \\
\hline CD8 & Presence/absence & Presence & TN \\
PD-L1 & $>5 \%$ membrane staining & Presence & TN \\
HER2 & $1+, 2+, 3+$ & $1+$ & $\mathrm{HER}^{+}$ \\
FOXP3 & $\begin{array}{l}\text { Low/High (above and } \\
\text { below median) }\end{array}$ & Low & $\mathrm{HR}^{+}$ \\
\hline
\end{tabular}

Abbreviations: $T N$ triple negative, $H R$ hormone receptor

atezolizumab (anti-PD-L1) inhibitor monotherapy, including some complete responders. The Keynote 012 trial reporting 27 patients with PD-L1 positive metastatic TN breast cancer treated with pembrolizumab as a monotherapy showed an overall response rate of $19 \%$ with one complete response and four partial responses as well as $26 \%$ patients with stable disease [32]. Similar results have been seen using anti-PD-L1 monoclonal antibodies. A trial of 21 metastatic TN breast cancer patients treated with atezolizumab monotherapy demonstrated a $19 \%$ overall response rate with two complete responses and two partial responses [33]. Early data has further demonstrated that combining chemotherapy and checkpoint inhibitor therapy may increase the number of clinical responses to immune checkpoint inhibitor therapy in TN breast cancer. In a study of 24 metastatic TN breast cancer patients, the combination of avelumab (anti-PD-L1) inhibitor and nabpaclitaxel showed a response rate of $42 \%$ (95\% CI 22.1 to $63.4 \%$ including a complete response rate of $4 \%$, partial response rate of $67 \%$, and stable disease in $21 \%$ of patients [34]. This data is promising, despite only 12 months of follow up, that use of checkpoint inhibitors in combination with chemotherapies may expand the number of breast cancer patients that respond to immune checkpoint inhibitor therapies particularly in TN breast cancer.

The number of patients with HER2 ${ }^{+}$and HR breast cancer subtypes who respond to immune checkpoint inhibitor therapy is much lower. In one study of 27 HER $2^{+}$ patients and $72 \mathrm{HR}$ patients receiving avelumab therapy, only $4 \%$ of HER $2^{+}$and $3 \%$ of HR patients demonstrated a clinical response [35]. In one study of 25 PD-L1 positive HR breast cancer patients treated with pembrolizumab, an overall response rate of $12 \%$ was observed and these were only partial responses [36]. Newer immune checkpoint therapies that activate the T-cell immune response rather than block inhibition of T-cell activity including OX40 (CD134), OX40 ligand, and 41BB (CD137) may be able to enhance immune-associated anti-tumor activity in breast cancer. In pre-clinical mouse mammary tumor models, treatment with either OX40 or 41BB monoclonal antibodies were able to significantly decrease both tumor growth and development of metastases [37-39]. Several clinical trials using combination checkpoint therapy are currently ongoing.

\section{Augmenting immunity through conventional breast cancer chemotherapy and monoclonal antibody therapy}

A major mechanism of action of trastuzumab therapy in HER $^{+}$breast cancer may be immunologic. Monoclonal antibodies can trigger antibody dependent cell mediated cytotoxicity (ADCC) that results in the activation of NK T-cells, macrophages, and dendritic cells. Activation of cells of the innate immune system leads to the secretion of Th1 cytokines, enhanced antigen processing, and presentation of endogenous tumor antigens to T-cells eliciting an adaptive immune response [40, 41]. Furthermore, the enhanced HER2 specific immunity associated with trastuzumab therapy has been associated with improve clinical prognosis. In a study of 87 locally advanced HER2 breast cancer patients treated with trastuzumab, $94 \%$ of the patients with high HER2 specific interferon gamma (IFN-g) Th1 immunity had pCR as compared to $33 \%$ of patients that did not achieve $\mathrm{pCR}(p=0.0002)$. In multivariate analysis, a high HER2-specific Th1 immune response predicted whether a patient would develop pCR (OR 8.82 $95 \%$ CI 1.50 to $51.83 p=0.016$ ) [42]. In an adjuvant chemotherapy trial of 95 HER2 breast cancer patients, high HER2-specific Th1 immunity predicted improved RFS (HR $16.995 \%$ CI 3.9 to $71.4 p<0.001$ ) [43]. Both of these studies found that trastuzumab was needed to stimulate increased Th1 HER2 specific immune responses as patients not treated with trastuzumab did develop the high Th1 HER2 specific immunity. Similarly in the FINHER study of 209 HER2 breast cancer patients, only patients that had been treated with trastuzumab had improved distant DFS with each $10 \%$ increase in TIL (HR $0.8295 \%$ CI 0.58 to $1.16, p=0.025 n=94$ ) [19]. For HER2 ${ }^{+}$breast cancer, the immunologic function of trastuzumab to induce type 1 immunity appears to be important for its therapeutic efficacy.

Cytotoxic chemotherapy has also been shown to increase type $1 \mathrm{~T}$-cell response. Some chemotherapeutic agents have been shown to trigger immune recognition of the tumor by induction of stress proteins released during cell death. For example doxorubicin induces the secretion of a protein called high-mobility-group box 1 (HMGB1) from dying cancer cells that binds to toll-like receptor (TLR) 4 on dendritic cells resulting in the secretion of IFN-g, antigen presentation, and activation of T-cells [44]. Tolllike receptors are highly conserved pattern recognition receptors that activate the immune recognition and enhance pathogen presentation to the adaptive immune system [45]. This resulting adaptive immune response may be a major mechanism of response to doxorubicin therapy because a TLR-4 genetic polymorphism, Asp299Gly, has been shown to decrease the binding of HMGB1 and IFN-g 
secretion by $50 \%(p<0.05)$ in in vitro assays. In an evaluation of 280 breast cancer patients treated with adjuvant doxorubicin, $40 \%$ of the patients carrying the TLR-4 Asp299Gly polymorphism developed metastatic disease in 5 years as compared to $27 \%$ of patients without the polymorphism (RR $1.5395 \%$ CI 1.1 to $3.59 p=0.03$ ) [44]. When comparing gene expression in 114 breast cancer patients that received anthracycline chemotherapy and 1062 breast cancer patients that did not receive chemotherapy, anthracycline therapy increased type 1 immune response, and the increased $\mathrm{CD}^{+}$(HR $0.7295 \%$ CI 0.59 to $0.82 p=0.005)$ and IFN-g (HR $0.5695 \% \mathrm{CI} 0.56$ to $0.89 p=0.016)$ expression was associated with improved pCR in patients that had been treated with anthracycline [46]. Paclitaxel has also been shown to increase tumor infiltrating type $1 \mathrm{~T}$-cells by increasing the expression of type 1 cytokines and decreasing Th2 CD4 ${ }^{+}$T-cells in the tumor $[47,48]$. Cyclophosphamide has been shown to decrease Th2 regulatory $\mathrm{T}$-cells without decreasing circulating Th1 immune response at low doses [49]. Carboplatin and cisplatin have been shown to increase MHC class 1 expression on the tumor while also decreasing intratumoral myeloid derived suppressor cells and Th2 regulatory T-cells in the tumor [50]. Studies are ongoing to determine the most effective way to dose or sequence these agents to optimize their immunologic effects.

\section{Newer options for immune modulation in breast cancer therapy}

Early clinical trials of metastatic breast cancer have demonstrated that localized therapies, including radiation, cryoablation, and cellular stress signals such as TLR agonists, both induce local destruction of the tumor as well as increase the systemic anti-tumor immune response demonstrating clinical response in tumors distant from the treated lesion. These distant responses occur because the local cellular damage increases cellular stress signals and trigger type 1 cytokine release, recruiting antigen presenting cells to the tumor and improving antigen presentation of tumor antigens to T-cells converting the tumor an in situ vaccine $[51,52]$. In a trial of 41 metastatic solid tumor patients treated with radiation and concurrent adjuvant granulocyte-macrophage colony-stimulating factor, 11 of 41 patients $(26.8 \%, 95 \%$ CI 14.2 to 49.9$)$ had a $30 \%$ reduction in the volume of non-irradiated tumors. Five of the 11 responding patients had breast cancer [53]. Similarly, cryoablation of breast tumors has been shown to increase type 1 cytokine secretion resulting in enhanced presentation of tumor-specific antigens to T-cells inducing a tumor-specific T-cell response [54, 55]. Cryoablation is currently in clinical trials along with ipilimumab in breast cancer and has shown both increase effector T-cell to regulatory $\mathrm{T}$-cell ratio and increase $\mathrm{T}$-cell clonal expansion in the tumor [56]. The TLR7 agonist imiquimod has been shown to induce partial response in $20 \%$ (95\% CI 3 to $56 \%$ ) of 10 breast cancer patients with skin metastases that are typically unresponsive to therapy [57]. For tumors with low immune infiltrate, local therapies can increase the systemic T-cell response against the tumor and therefore increase the anti-tumor immune response to areas of disease distant from the therapy.

\section{Conclusion}

With evidence that the magnitude and composition of tumor immune infiltrate can affect prognosis and response to therapy both for DCIS and invasive cancer, the pretherapy tumor immune environment can be used both as a biomarker for the prognosis of an individuals' disease as well as a guide to determine what is the most appropriate therapy. Currently, the International TILs Working Group has started standardizing evaluation of breast cancer TILs to be able to use this in clinical practice [58]. Standardizing how to characterize a breast tumor by both the subtype and immune environment (having high, intermediate, or low immune infiltrate) will allow both the identification of patients that may only need treatment with various emerging immune therapies (including checkpoint inhibitor therapy) and provide the optimal combinations and timing of these powerful therapies to the patients with lower immune infiltrate to allow a wider population of breast cancer patients to benefit from targeted immune therapy.

\section{Abbreviations \\ DCIS: Ductal carcinoma in situ; DFS: Disease free survival; HER ${ }^{+}$: HER2 positive; HR: Hormone receptor positive HER2 negative; IFN-g: Interferon gamma; LPBC: Lymphocyte predominant breast cancer; OS: Overall survival; pCR: Pathologic complete response; RFS: Relapse free survival; Th1: Type 1 helper T-cells; Th2: Type 2 helper T-cells; TIL: Tumor infiltrating lymphocytes; TN: Triple negative}

\section{Acknowledgements \\ The authors thank Chad Boyer BS of the University of Washington Tumor Vaccine Group for his invaluable assistance with formatting.}

Availability of data and materials

Not Applicable.

\section{Authors' contributions}

SES and MLD drafted and critically revised the manuscript. Both authors read and approved the final manuscript.

\section{Authors' information}

Not Applicable.

\section{Competing interests}

Dr. Mary L. Disis has a commercial research grant from EMD Serono, Seattle Genetics, Celgene, and Ventrix and ownership interest in Epithany and Ventrix. She is a patent holder at the University of Washington. The authors declare that they have no competing interests.

Consent for publication

Not Applicable.

Ethics approval and consent to participate Not Applicable. 


\section{Research support}

M.L. Disis was supported by the Athena Distinguished Professor of Breast Cancer Research, Komen Leadership Award and DOD W81XWH-11-1-0760. S.E. Stanton was supported by NIH KL2TR000421.

\section{Received: 13 June 2016 Accepted: 13 September 2016} Published online: 18 October 2016

\section{References}

1. Pages F, Kirilovsky A, Mlecnik B, Asslaber M, Tosolini M, Bindea G, et al. In situ cytotoxic and memory T cells predict outcome in patients with early-stage colorectal cancer. J Clin Oncol. 2009;27(35):5944-51. doi:10.1200/JCO.2008.19.6147.

2. Hwang WT, Adams SF, Tahirovic E, Hagemann IS, Coukos G. Prognostic significance of tumor-infiltrating T cells in ovarian cancer: a meta-analysis. Gynecol Oncol. 2012;124(2):192-8. doi:10.1016/j.ygyno.2011.09.039.

3. Dieu-Nosjean MC, Antoine M, Danel C, Heudes D, Wislez M, Poulot V, et al. Long-term survival for patients with non-small-cell lung cancer with intratumoral lymphoid structures. J Clin Oncol. 2008;26(27):4410-7. doi:10.1200/JCO.2007.15.0284

4. Denkert C, Loibl S, Noske A, Roller M, Muller BM, Komor M, et al. Tumorassociated lymphocytes as an independent predictor of response to neoadjuvant chemotherapy in breast cancer. J Clin Oncol. 2010;28(1):105-13. doi:10.1200/JCO.2009.23.7370.

5. Loi S, Sirtaine N, Piette F, Salgado R, Viale G, Van Eenoo F, et al. Prognostic and predictive value of tumor-infiltrating lymphocytes in a phase III randomized adjuvant breast cancer trial in node-positive breast cancer comparing the addition of docetaxel to doxorubicin with doxorubicinbased chemotherapy: BIG 02-98. J Clin Oncol. 2013;31(7):860-7. doi:10.1200/JCO.2011.41.0902.

6. Zitvogel L, Galluzzi L, Kepp O, Smyth MJ, Kroemer G. Type I interferons in anticancer immunity. Nat Rev Immunol. 2015;15(7):405-14. doi:10.1038/nri3845.

7. Tan AH, Goh SY, Wong SC, Lam KP. T helper cell-specific regulation of inducible costimulator expression via distinct mechanisms mediated by T-bet and GATA-3. J Biol Chem. 2008;283(1):128-36. doi:10.1074/jbc.M707693200.

8. Hussein MR, Hassan HI. Analysis of the mononuclear inflammatory cell infiltrate in the normal breast, benign proliferative breast disease, in situ and infiltrating ductal breast carcinomas: preliminary observations. J Clin Pathol. 2006;59(9):972-7. doi:10.1136/jcp.2005.031252.

9. Thompson E, Taube JM, Elwood H, Sharma R, Meeker A, Warzecha HN, et al. The immune microenvironment of breast ductal carcinoma in situ. Mod Pathol. 2016:29(3):249-58. doi:10.1038/modpathol.2015.158.

10. Bates GJ, Fox SB, Han C, Leek RD, Garcia JF, Harris AL, et al. Quantification of regulatory $T$ cells enables the identification of high-risk breast cancer patients and those at risk of late relapse. J Clin Oncol. 2006;24(34):5373-80. doi:10.1200/JCO.2006.05.9584

11. Kristensen VN, Vaske CJ, Ursini-Siegel J, Van Loo P, Nordgard SH, Sachidanandam R, et al. Integrated molecular profiles of invasive breast tumors and ductal carcinoma in situ (DCIS) reveal differential vascular and interleukin signaling. Proc Natl Acad Sci U S A. 2012;109(8):2802-7. doi:10.1073/pnas.1108781108

12. Marquez JP, Stanton SE, Disis ML. The antigenic repertoire of premalignant and high-risk lesions. Cancer Prev Res (Phila). 2015;8(4):266-70. doi:10.1158/1940-6207.capr-14-0314.

13. Mahmoud SM, Paish EC, Powe DG, Macmillan RD, Grainge MJ, Lee AH, et al. Tumor-infiltrating CD8+ lymphocytes predict clinical outcome in breast cancer. J Clin Oncol. 2011;29(15):1949-55. doi:10.1200/JCO.2010.30.5037.

14. Baker K, Lachapelle J, Zlobec I, Bismar TA, Terracciano L, Foulkes WD. Prognostic significance of CD8+ T lymphocytes in breast cancer depends upon both oestrogen receptor status and histological grade. Histopathology. 2011;58(7):1107-16. doi:10.1111/j.1365-2559.2011.03846.x.

15. Liu S, Lachapelle J, Leung S, Gao D, Foulkes WD, Nielsen TO. CD8+ lymphocyte infiltration is an independent favorable prognostic indicator in basal-like breast cancer. Breast Cancer Res. 2012;14(2):R48. doi:10.1186/bcr3148.

16. Oda N, Shimazu K, Naoi Y, Morimoto K, Shimomura A, Shimoda M, et al. Intratumoral regulatory $T$ cells as an independent predictive factor for pathological complete response to neoadjuvant paclitaxel followed by 5-FU/epirubicin/cyclophosphamide in breast cancer patients. Breast Cancer Res Treat. 2012;136(1):107-16. doi:10.1007/s10549-012-2245-8.

17. Mulligan AM, Pinnaduwage D, Tchatchou S, Bull SB, Andrulis IL. Validation of Intratumoral T-bet + Lymphoid Cells as Predictors of Disease-Free
Survival in Breast Cancer. Cancer Immunol Res. 2016;4(1):41-8. doi:10.1158/2326-6066.CIR-15-0051.

18. Adams S, Gray RJ, Demaria S, Goldstein LJ, Perez EA, Shulman LN, et al. Prognostic Value of Tumor-Infiltrating Lymphocytes (TILs) in Triple Negative Breast Cancers (TNBC) from two Phase III Randomized Adjuvant Breast Cancer Trials: ECOG 2197 and ECOG 1199. J Clin Oncol. 2014;32:2959-66.

19. Loi S, Michiels S, Salgado R, Sirtaine N, Jose V, Fumagalli D, et al. Tumor infiltrating lymphocytes is prognostic and predictive for trastuzumab benefit in early breast cancer: results from the FinHER trial. Ann Oncol. 2014. doi:10.1093/annonc/mdu112

20. Dieci MV, Mathieu MC, Guarneri V, Conte P, Delaloge S, Andre F, et al. Prognostic and predictive value of tumor-infiltrating lymphocytes in two phase III randomized adjuvant breast cancer trials. Ann Oncol. 2015;26(8):1698-704. doi:10.1093/annonc/mdv239.

21. Stanton S, Adams S, Disis M. Variation in the incidence and magnitude of tumor infiltrating lymphocytes in breast cancer subtypes: A systematic review. JAMA oncology. 2016:in press.

22. Ladoire S, Arnould L, Mignot G, Apetoh L, Rebe C, Martin F, et al. T-bet expression in intratumoral lymphoid structures after neoadjuvant trastuzumab plus docetaxel for HER2-overexpressing breast carcinoma predicts survival. Br J Cancer. 2011;105(3):366-71. doi:10.1038/bjc.2011.261.

23. Jiang X, Ellison SJ, Alarid ET, Shapiro DJ. Interplay between the levels of estrogen and estrogen receptor controls the level of the granzyme inhibitor, proteinase inhibitor 9 and susceptibility to immune surveillance by natural killer cells. Oncogene. 2007;26(28):4106-14. doi:10.1038/sj.onc.1210197.

24. Mostafa AA, Codner D, Hirasawa K, Komatsu Y, Young MN, Steimle V, et al. Activation of ERalpha signaling differentially modulates IFN-gamma induced HLA-class II expression in breast cancer cells. PLoS One. 2014;9(1):e87377. doi:10.1371/journal.pone.0087377.

25. West NR, Kost SE, Martin SD, Milne K, Deleeuw RJ, Nelson BH, et al. Tumourinfiltrating FOXP3(+) lymphocytes are associated with cytotoxic immune responses and good clinical outcome in oestrogen receptor-negative breast cancer. Br J Cancer. 2013;108(1):155-62. doi:10.1038/bjc.2012.524.

26. Cimino-Mathews A, Thompson E, Taube JM, Ye X, Lu Y, Meeker A, et al. PD-L1 (B7-H1) expression and the immune tumor microenvironment in primary and metastatic breast carcinomas. Hum Pathol. 2016:47(1):52-63. doi:10.1016/j.humpath.2015.09.003.

27. Mittendorf EA, Philips AV, Meric-Bernstam F, Qiao N, Wu Y, Harrington S, et al. PD-L1 expression in triple-negative breast cancer. Cancer Immunol Res. 2014;2(4):361-70. doi:10.1158/2326-6066.CIR-13-0127.

28. Wimberly H, Brown JR, Schalper K, Haack H, Silver MR, Nixon C, et al. PD-L1 Expression Correlates with Tumor-Infiltrating Lymphocytes and Response to Neoadjuvant Chemotherapy in Breast Cancer. Cancer Immunol Res. 2015;3(4):326-32. doi:10.1158/2326-6066.CIR-14-0133.

29. Schalper KA, Velcheti V, Carvajal D, Wimberly H, Brown J, Pusztai L, et al. In situ tumor PD-L1 mRNA expression is associated with increased TILs and better outcome in breast carcinomas. Clin Cancer Res. 2014:20(10):2773-82. doi:10.1158/1078-0432.CCR-13-2702.

30. Topalian SL, Hodi FS, Brahmer JR, Gettinger SN, Smith DC, McDermott DF, et al. Safety, activity, and immune correlates of anti-PD-1 antibody in cancer. N Engl J Med. 2012;366(26):2443-54. doi:10.1056/NEJMoa1200690.

31. Vonderheide RH, LoRusso PM, Khalil M, Gartner EM, Khaira D, Soulieres D, et al. Tremelimumab in combination with exemestane in patients with advanced breast cancer and treatment-associated modulation of inducible costimulator expression on patient T cells. Clin Cancer Res. 2010;16(13):3485-94. doi:10.1158/1078-0432.CCR-10-0505.

32. Nanda R, Chow LQ, Dees EC, Berger R, Gupta S, Geva R, et al. Pembrolizumab in Patients With Advanced Triple-Negative Breast Cancer: Phase Ib KEYNOTE-012 Study. J Clin Oncol. 2016. doi:10.1200/JCO.2015.64.8931.

33. Emens LA, Braiteh FS, Cassier P, De Lord J-P, Eder JP, Shen $X$, et al. Abstract PD1-6: Inhibition of PD-L1 by MPDL3280A leads to clinical activity in patients with metastatic triple-negative breast cancer. Philadelphia: American Association of Cancer Research; 2014.

34. Adams S, Card D, Zhao J, Karantza V, Aktan G. A phase 2 study of pembrolizumab (MK-3475) monotherapy for metastatic triple-negative breast cancer (mTNBC): KEYNOTE-086. San Antonio Breast Cancer Symposium. 2015

35. Dirix, LY, Takacs, I, Nikolinakos, P et al. Avelumab (MSB0010718C), an antiPD-L1 antibody, in patients with locally advanced or metastatic breast cancer: A phase Ib JAVELIN solid tumor trial. San Antonio Breast Cancer Symposium. 2015 
36. Rugo HS, Delord J-P, Im S-A, Ott PA, Piha-Paul SA, Bedard PL et al. Preliminary efficacy and safety of pembrolizumab (MK-3475) in patients with PD-L1positive, estrogen receptor-positive (ER+)/HER2-negative advanced breast cancer enrolled in KEYNOTE-028. San Antonio Breast Cancer Symposium. 2015.

37. Garrison K, Hahn T, Lee WC, Ling LE, Weinberg AD, Akporiaye ET. The small molecule TGF-beta signaling inhibitor SM16 synergizes with agonistic OX40 antibody to suppress established mammary tumors and reduce spontaneous metastasis. Cancer Immunol Immunother. 2012;61(4):511-21. doi:10.1007/s00262-011-1119-y.

38. Stagg J, Loi S, Divisekera U, Ngiow SF, Duret H, Yagita H, et al. Anti-ErbB-2 mAb therapy requires type I and II interferons and synergizes with anti-PD-1 or anti-CD137 mAb therapy. Proc Natl Acad Sci U S A. 2011;108(17):7142-7. doi:10.1073/pnas.1016569108.

39. Kohrt HE, Houot R, Weiskopf K, Goldstein MJ, Scheeren F, Czerwinski D, et al. Stimulation of natural killer cells with a CD137-specific antibody enhances trastuzumab efficacy in xenotransplant models of breast cancer. J Clin Invest. 2012;122(3):1066-75. doi:10.1172/JCl61226.

40. Arnould L, Gelly M, Penault-Llorca F, Benoit L, Bonnetain F, Migeon C, et al. Trastuzumab-based treatment of HER2-positive breast cancer: an antibodydependent cellular cytotoxicity mechanism? Br J Cancer. 2006;94(2):259-67. doi:10.1038/sj.bjc.6602930.

41. Shi Y, Fan X, Deng H, Brezski RJ, Rycyzyn M, Jordan RE, et al. Trastuzumab triggers phagocytic killing of high HER2 cancer cells in vitro and in vivo by interaction with Fcgamma receptors on macrophages. J Immunol. 2015;194(9):4379-86. doi:10.4049/jimmunol.1402891.

42. Datta J, Berk E, Xu S, Fitzpatrick E, Rosemblit C, Lowenfeld L, et al. Anti-HER2 CD4(+) T-helper type 1 response is a novel immune correlate to pathologic response following neoadjuvant therapy in HER2-positive breast cancer. Breast Cancer Res. 2015;17:71. doi:10.1186/s13058-015-0584-1.

43. Datta J, Fracol M, McMillan MT, Berk E, Xu S, Goodman N, et al. Association of Depressed Anti-HER2 T-Helper Type 1 Response With Recurrence in Patients With Completely Treated HER2-Positive Breast Cancer: Role for Immune Monitoring. JAMA Oncol. 2016;2(2):242-6. doi:10.1001/jamaoncol.2015.5482.

44. Apetoh L, Ghiringhelli F, Tesniere A, Obeid M, Ortiz C, Criollo A, et al. Toll-like receptor 4-dependent contribution of the immune system to anticancer chemotherapy and radiotherapy. Nat Med. 2007;13(9):1050-9. doi:10.1038/nm1622.

45. Hemmi H, Kaisho T, Takeuchi O, Sato S, Sanjo H, Hoshino K, et al. Small anti-viral compounds activate immune cells via the TLR7 MyD88-dependent signaling pathway. Nat Immunol. 2002;3(2):196-200. doi:10.1038/ni758.

46. Mattarollo SR, Loi S, Duret H, Ma Y, Zitvogel L, Smyth MJ. Pivotal role of innate and adaptive immunity in anthracycline chemotherapy of established tumors. Cancer Res. 2011;71(14):4809-20. doi:10.1158/0008-5472.CAN-11-0753.

47. Fleming GF, Meropol NJ, Rosner GL, Hollis DR, Carson 3rd WE, Caligiuri M, et al. A phase I trial of escalating doses of trastuzumab combined with daily subcutaneous interleukin 2: report of cancer and leukemia group B 9661. Clin Cancer Res. 2002;8(12):3718-27.

48. Tsavaris N, Kosmas C, Vadiaka M, Kanelopoulos P, Boulamatsis D. Immune changes in patients with advanced breast cancer undergoing chemotherapy with taxanes. Br J Cancer. 2002;87(1):21-7. doi:10.1038/sj.bjc.6600347.

49. Lutsiak ME, Semnani RT, De Pascalis R, Kashmiri SV, Schlom J, Sabzevari H. Inhibition of CD4(+)25+ T regulatory cell function implicated in enhanced immune response by low-dose cyclophosphamide. Blood. 2005;105(7):2862-8. doi:10.1182/blood-2004-06-2410.

50. Wan S, Pestka S, Jubin RG, Lyu YL, Tsai YC, Liu LF. Chemotherapeutics and radiation stimulate $\mathrm{MHC}$ class I expression through elevated interferonbeta signaling in breast cancer cells. PLoS One. 2012;7(3):e32542. doi:10.1371/journal.pone.0032542.

51. Reits EA, Hodge JW, Herberts CA, Groothuis TA, Chakraborty M, Wansley EK, et al. Radiation modulates the peptide repertoire, enhances MHC class I expression, and induces successful antitumor immunotherapy. J Exp Med. 2006;203(5):1259-71. doi:10.1084/jem.20052494.

52. Apetoh L, Ghiringhelli F, Tesniere A, Criollo A, Ortiz C, Lidereau R, et al. The interaction between HMGB1 and TLR4 dictates the outcome of anticancer chemotherapy and radiotherapy. Immunol Rev. 2007;220:47-59. doi:10.1111/j.1600-065X.2007.00573.x.

53. Golden EB, Chhabra A, Chachoua A, Adams S, Donach M, Fenton-Kerimian M, et al. Local radiotherapy and granulocyte-macrophage colony-stimulating factor to generate abscopal responses in patients with metastatic solid tumours: a proof-of-principle trial. Lancet Oncol. 2015:16(7):795-803. doi:10.1016/S1470-2045(15)00054-6.
54. Zynda ER, Grimm MJ, Yuan M, Zhong L, Mace TA, Capitano M, et al. A role for the thermal environment in defining co-stimulation requirements for CD4(+) T cell activation. Cell Cycle. 2015;14(14):2340-54. doi:10.1080/15384101.2015.1049782

55. Sabel MS, Nehs MA, Su G, Lowler KP, Ferrara JL, Chang AE. Immunologic response to cryoablation of breast cancer. Breast Cancer Res Treat. 2005;90(1):97-104. doi:10.1007/s10549-004-3289-1.

56. Page DB, Diab A, Juan J, Dong Z, Solomon SB, Patil S et al., editors. Preoperative immunotherapy with tumor cryoablation (cryo) plus ipilimumab (ipi) induces potentially favorable systemic and intratumoral immune effects in early stage breast cancer (ESBC) patients. Breast Cancer Immunotherapy Symposium; 2015; Doha, Qatar.

57. Adams S, Kozhaya L, Martiniuk F, Meng TC, Chiriboga L, Liebes L, et al. Topical TLR7 agonist imiquimod can induce immune-mediated rejection of skin metastases in patients with breast cancer. Clin Cancer Res. 2012;18(24):6748-57. doi:10.1158/1078-0432.CCR-12-1149.

58. Salgado R, Denkert C, Demaria S, Sirtaine N, Klauschen F, Pruneri G, et al. The evaluation of tumor-infiltrating lymphocytes (TILS) in breast cancer: recommendations by an International TILs Working Group 2014. Ann Oncol. 2015:26(2):259-71. doi:10.1093/annonc/mdu450.

\section{Submit your next manuscript to BioMed Central and we will help you at every step:}

- We accept pre-submission inquiries

- Our selector tool helps you to find the most relevant journal

- We provide round the clock customer support

- Convenient online submission

- Thorough peer review

- Inclusion in PubMed and all major indexing services

- Maximum visibility for your research

Submit your manuscript at www.biomedcentral.com/submit
) Biomed Central 